
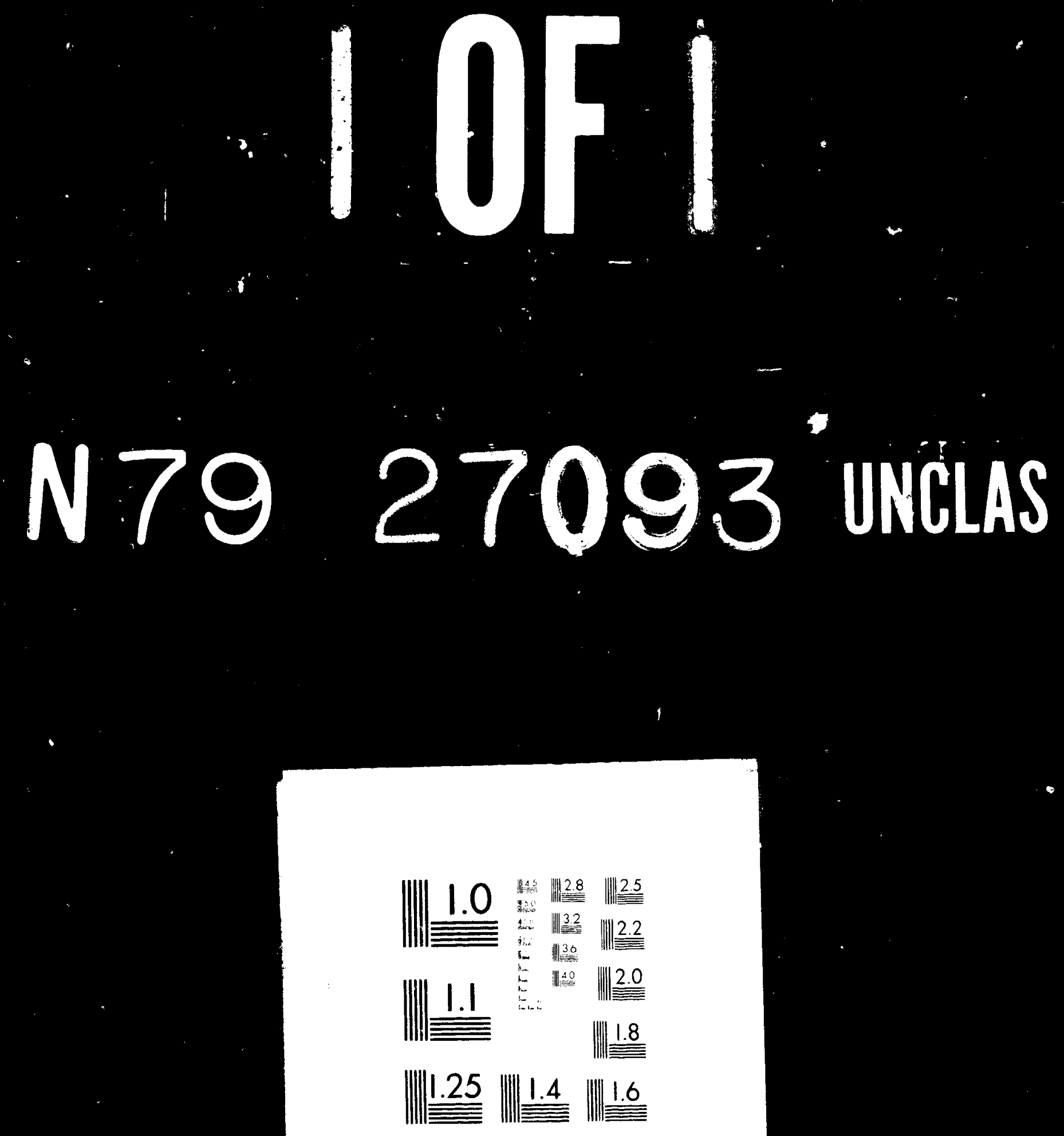

MICROCOPY RLSOLUTION IEST CHARI 
NASA Technical Memorandum 79176

(MASA-TH-79176) PERFORAANCE OF A V/STOL

TILT NACELLE INLET WITH BLORING BOONDARY

N79-27093

LAYER CONTROL (MASA) 13 P HC AO2/MF AOI

$\operatorname{Csc} 2011$

G3/02 Inclas 29271

\title{
PERFORMANCE OF A V/STOL TILT \\ NACELLE INLET WITH BLOWING \\ BOUNDARY LAYER CONTROL
}

\author{
Albert L. Johns and Robert C. Williams \\ Lewis Research Center \\ Cleveland, Ohio \\ and \\ H. C. Potonides \\ Grumman Aerospace Corporation \\ Bethpage, New York 11714
}

Prepared for the

Fifternth Joint Propulsion Conference

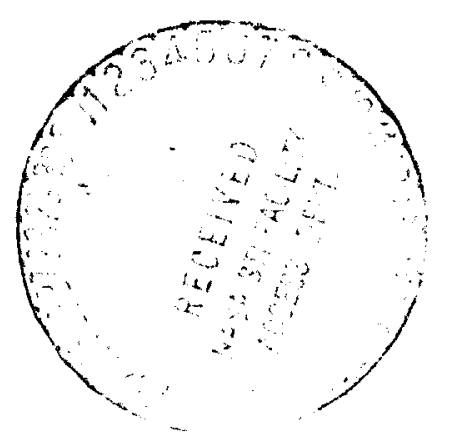

cosponsored by the American Institute of Aeronautics and Astronautics, the Society of Automotive Engineers, and the American Society of Mr chanical Engineers

Las Vegas, Nevada, June 18-20, 1979 


\author{
PERFORMANCE OF A V/STOL TIIT NACELIE INLET \\ WITH BLOWING BOUNDARY LAYER CONTROL \\ by Albert L. Johns and Robert C. Williams \\ Lewis Research Center \\ cleveland, Ohio 44135 \\ and \\ H. C. Potonides \\ Grumman Aerospace Corporation \\ Bethpage, New York 11714
}

\title{
INTRODUCTION
}

The propulsion systen for tilt nacelle V/Siol aircraft must operate efficiently and smoothly over a wide range of flight speeds, engine weight flows and incidence angles. For example, during the approach to landing (fig. 1), the nacelles rotate from the normal horizontal position to an angle of $99^{\circ}$. Rotating the nacelles to these high agles reault in correspondingly high angles of flow incidence at the inlets.

If the fan is to perform satisfactorily, the inlet must meet the requirements listed in figure 2. For high thrust and engine efficiency, the inlet pressure recovery must be high and the inlet flow distortion low. These two requirements are usually met simultaneously. For the fan blade stresses to be low, the distortion must be low. For acceptable airplane handling qualities and control, any variations in the pressure recovery and distortion that do occur must be smooth, that is, not discontinuous. Generally, an inlet with attached flow will satisfy the above requirements. There are however some levels and degrees of separation that may be acceptable for certain engines.

\section{SYMBOLS}

$\begin{array}{ll}\text { Blg. P.R. } & \text { Blowing pressure ratio, } \mathrm{P}_{\mathrm{P}} / \mathrm{P}_{\infty} \\ \mathrm{CR} & \text { inlet area contraction ratio }\left(\mathrm{R}_{\mathrm{hL}} / \mathrm{R}_{\mathrm{t}}\right)^{2} \\ \mathrm{D}_{\mathrm{f}} & \text { fan face diameter } 50.8 \mathrm{~cm}(20.00 \mathrm{in.}) \\ \mathrm{D}_{\mathrm{hL}} & \text { hilite diameter } 53.87 \mathrm{~cm}(21.208 \mathrm{in.}) \\ \mathrm{L} & \text { inlet axial length } 30.63 \mathrm{~cm}(12.059 \mathrm{in.}) \\ \mathrm{M}_{\mathrm{t}} & \text { inlet throat Mach number } \\ \mathrm{N} & \text { fan rotational speed } \\ \mathrm{P}_{\mathrm{P}} & \text { blowing plenum pressure } \\ \mathrm{P}_{\infty} & \text { free stream total pressure } \\ \overline{\mathrm{P}}_{2} / \mathrm{P}_{\infty} & \text { fan face area weighted total pressure recovery } \\ \mathrm{R}_{t} & \text { local throat radius, cm (in.) }\end{array}$




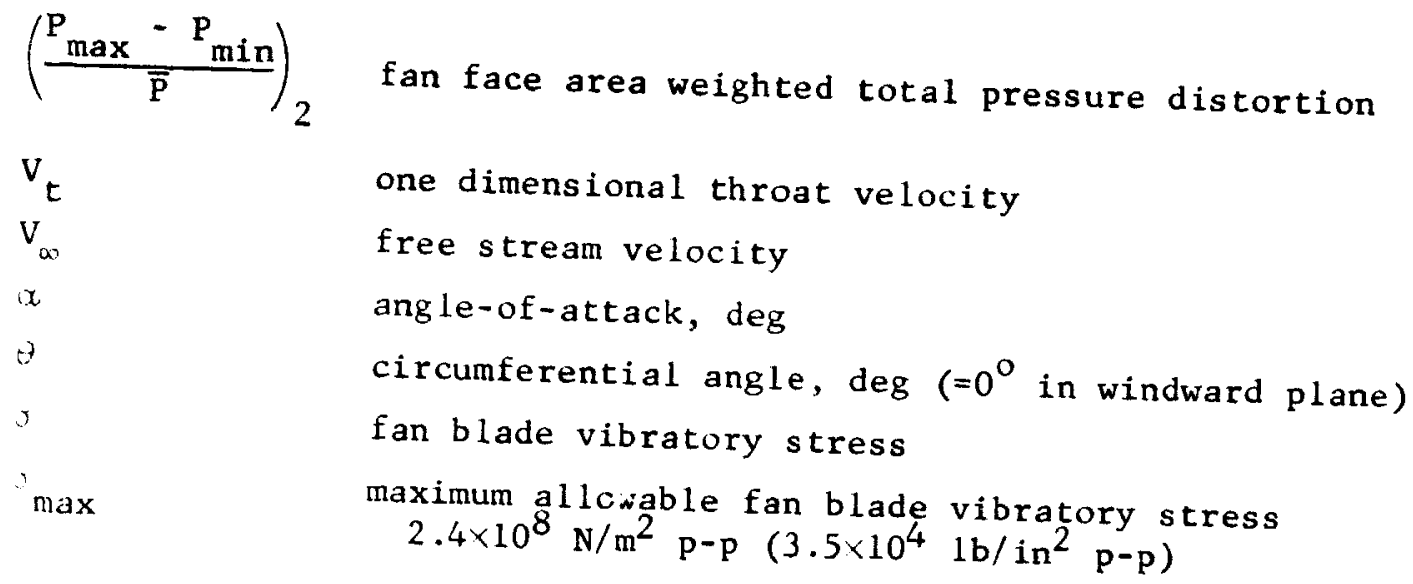

\section{APPARATUS}

At NASA Lewis Research Center several concepts have been evaluated that would extend the tilt nacelle/inlet attached flow operating range. (Thick lips, scarf inlets, centerbody location, etc.). These concepts are discussed in the references.

This paper presents the experimental results of a Grumman Aerospace Corporation/Lewis V/stol inlet with blowing boundary layer control which whis tested in the NASA Lewis $9 \times 15$ ft Low speed Wind Tunnel (fig. 3). by Gruman Aerospace Corporation model of a fixed geometry inlet designed inlet/nacelle model was testion for tilt nacelle V/SToL aircraft. The fan. This is a single stage with an existing (20 in.) $30.48 \mathrm{~cm}$ diameter speed representative of a V/STan which has a pressure ratio and a tip

The goal was to ascertain the incraft application.

speed inlet operating envelope the inlet/fan performance over the low $\left.0^{\circ} \leq \alpha \leq 120^{\circ}\right)$. The model rotate $\leq \mathrm{V}_{\mathrm{o}} \leq 64 \mathrm{~m} / \mathrm{sec}$ (125 knots), vertical support post. This post in the horizontal plane about the pressure turbine drive air. (The windwardides the passage for the high

The blowing air supply line windward plane is labeled in the slide.) mounted with a swivel joint. A portion from the top of the tunnel and is removed to allow the fan and A portion of the adajcent vertical wall was angles of attack. an asymmetric design with in details and instrumentation. The inlet is a leeward-side contraction watio of -side contraction rati of 1.69 and fined as $\left(R_{h L} / R_{t}\right)^{2}$.

The blowi

and extends $120^{\circ}$ s of the inlet throat height was $\approx 0.012$ inches. surface. The diffuser wall anglewing direction was tangent to the inlet The fan face diameter was 3 ( ratio $\left(L / D_{f}\right)$ was 0.603 . were used to measure the fan were located ahead of the fan. These rakes A wall static and the lower fotal total pressure recovery and distortion. separation. 
Data were taken from $0 \leq v_{0} \leq 64 \mathrm{~m} / \mathrm{sec}$ (125 knots), $0^{\circ} \leq a \leq 120^{\circ}$ and blowing pressure ratios $\bar{f}$ rom $\overline{0} .99 \leq \mathrm{P}_{\mathrm{P}} / \mathrm{P}_{\mathrm{O}} \leq 2.00$.

\section{RESULTS AND DISCUSS ION}

What can a small amount of blowing do for the inlet angle-of-attack $(\alpha)$ operating range?

Figure 5 answers this question. Shown is the inlet angle-of-attack plotted against the throat-to-freestream velocity ratio for both the nonblowing and blowing inlets. The blowing inlet had a blowing pressure ratio $\left(\mathrm{P}_{\mathrm{p}} / \mathrm{P}_{\infty}\right)$ of 1.40 ( $5 \%$ of inlet mass $\mathrm{flow}$ ). Separation-free (attached) flow is to the right of each curve.

With no blowing, at a velocity ratio of 2.5 , the maximum $\alpha$ of separation-free flow is $\approx 61^{\circ}$. However, with blowing the maximum angle-ofattack is $110^{\circ}$. This result applies to the 1 ow speed, $31 \mathrm{~m} / \mathrm{sec}(60 \mathrm{knots})$. This is a tremendous improvement in the separation-free operation of the inlet.

The blowing curve includes points for four freestream velocities. The data tends to correlate with the throat-to-freestream velocity ratio $\left(V_{t} / V_{\infty}\right)$ is the reglos were compreas billity of foct $f$ pot a fector.

Pigure 6 hot the inlet opetating ranto from pht-to-fall

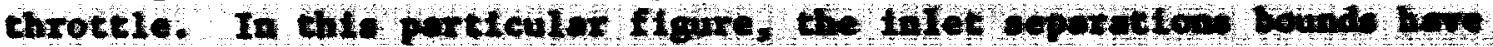
been cowpared to the fan operating range. The tight hand curve reprepente full-throttle (100\% fan speed) and the left hand curve ts part-throttle (40\% fan speed). These curves represent a range of freestrean velocities. In general, with blowing the inlet would operate in the attached flow region over the operating range from part to full throttle.

Typteal attachment/separtion occurring wth blowing to shown in figure 7. Total pressure recovery and distortion at the fan face is plotted versus the one-dimenstonal inlet throat Mach number. The data is shown for $V_{\infty}$ of $41 \mathrm{~m} / \mathrm{sec}(80 \mathrm{knots})$ and $\alpha$ of $75^{\circ}$. Attachment occurs with increasing $M_{t}(\mathrm{rpm})$. Separation occurs with decreasing $M_{t}(\mathrm{rpm})$. The solid symbols denote separated flow.

With decreasing throat Mach number, the flow separation occurred at a significantly lower throat Mach number than it attached with increasing throat Mach number. This is a stable hysteresis which was typical with blowing. However, the baseline (nonblowing) inlet had negligible hysteresis.

The fan face distortion also exhibited a stable hysteresis. As throat Mach number ( $\mathrm{rpm}$ ) increased the fan face distortion increased (responding to separated flow) anil decreased when the flow attached. However, with decreasing throat Mack number ( $\mathrm{rpm}$ ) the flow remains attached to a lower throat Mach number with a corresponding lower fan face distortion.

For a particular set of inlet condition ( $V_{\infty}, \alpha=$ const. with rpm varying from maximum to minimum) the following occurs:

(a) From maximum $\mathrm{rpm}$ to (rpm) separation, the pressure recovery increases and distortion dećreases.

(b) From (rpm) separation to rpm where separated flow occurs over a small part of the fan face, the pressure recovery decreases and distortion increases. 
(c) When the inlet is completely separated both pressure recovery and distortion decrease.

It is interesting to note, that when attachment or separation occurs there is an abrupt change in the pressure recovery and distortion. Data pertaining to the separation point (decreasing rpm) will be the topic of the remaining discussion.

Figure 8 shows the effect of blowing pressure ratio on iniet separation. This figure shows: the total pressure recovery and fan face distortion versus throat Mach number $\left(M_{t}\right)$ at $V_{x}=41 \mathrm{~m} / \mathrm{sec}$ ( 80 knots) and $\therefore=75^{\circ}$, the same condition as the previous figure. Data for the baseline (nonblowing) inlet are given by the symbols. Solid symbols denotes separated flow. The baseline (nonblowing) inlet was separated from a throat Mach number of 0.15 to 0.375 . There is also a region from 0.250 to 0.325 where the inlet flow and $f$ an $r p m$ are unstable.

For the blowing inlet, blowing pressure ratios of $1.2,1.4$ and 1.7 are shown. The blowing pressure ratio is defined as $P_{p} / P_{\infty}$. A large incremental gain in the attached flow throat Mach number range occurred with a blowing pressure ratio of 1.2 (maximum of $4.3 \%$ inlet flow). However, the higher blowing pressure ratios do modestly increase the level of recovery and the range of attached flow.

As tesult of the separation polnt occurring ot lower throut wach number the region of smooth thrust modulation is increased with blowing. Blowing also resulted in a reduction in fan face distortion which is analogous to the pressure recovery increase.

Figure 9 shows the effect of blowing on fan blade streses for $V_{\infty}=64 \mathrm{~m} / \mathrm{sec}$ ( 125 knots), $x=55^{\circ}$. The first, flatwise bending mode stress aignature is hown as arcentage of the maximum allowable stress versus the fan rotational speed (N).

The stress signature can be characterized as having two components: a broadband level superimposed on wich are a series of discrete narrow speed band peaks. With the baseline configuration these discrete narrow peaks correspond to integral numbers of blade vibration cycles per revolution (ViB/REV).

With the nonblowing inlet the 3,4 , and 5 vibration per rev. were of a significant level. Of particular concern was the 4 vih. per rev. which was near $100 \%$ of the allowable stress. However, with the $120^{\circ}$ blowing (Blg. P.R. of $1.4-5 \%$ of inlet mass flow) the blade stress peaks were
eradicated.

SUMMARY

The major effects of blowing on boundary layer control of a tiltnacelle V/STOL inlet are:

1. Angle-of-attack range increased.

2. Blade stresses significantly reduced.

3. Fan face distortion reduced. 
5

REFERENCES

1. Shaw, R. J., Williams, R. C., and Koncsek, J. L., "V/STOL Tilt Nacelle Aerodynamics and its Relation to Fan Blade Stresses," NASA TM-7889,, 1978.

2. Abbott, J. M., "Aerodynamics Performance of Scarf Inlets," NASA TM-79055, 1979.

3. Burley, R. R., "Effect of Lip and Centerbody Geometry on Aerodynamic Performance of Inlets for Tilting-Nacel le VTOL Aircraft," NASA TM-79056, 1979.

4. Potonides, H. C., Lea, R. A., and Nelson, T. F., "Design and Experimental Studies of a Type "A" V/STOL Inlet," AIAA Paper 78-956, July

5. Lewis, G. W., Jr., and Ty 1, E. R., "Overall and Blade-Element Perfornance of a 1.20-Pressure-Ratio Fan Stage at Design Blade Setting Angle,"
NASA TM X-3101, 1974. 


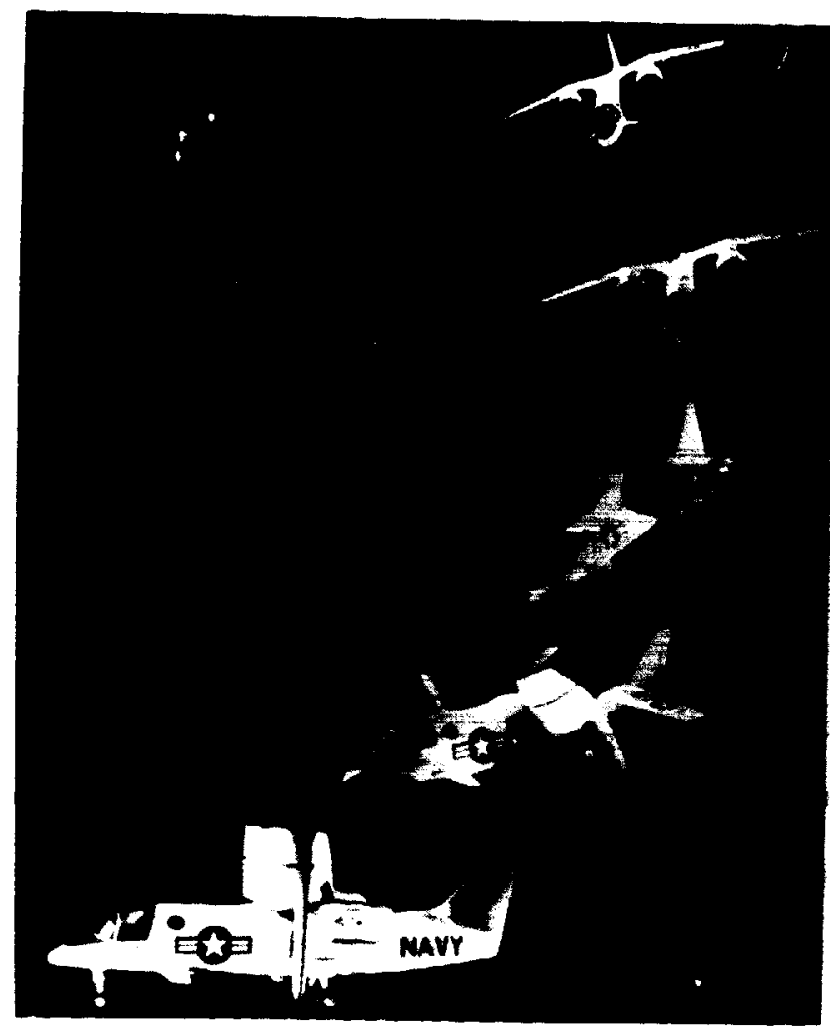

Figure 1. - Representative landinq approach for tilt-narcelle VTOL aircraft 


\title{
INLET REQUIREMENTS
}

\author{
HIGH PRESSURE RECOVERY \\ LOW DISTORTION LEVELS \\ LOW BLADE STRESSES
}

SMOOTH THRUST VARIATIONS

Figure 2. - Inlet requirements. 


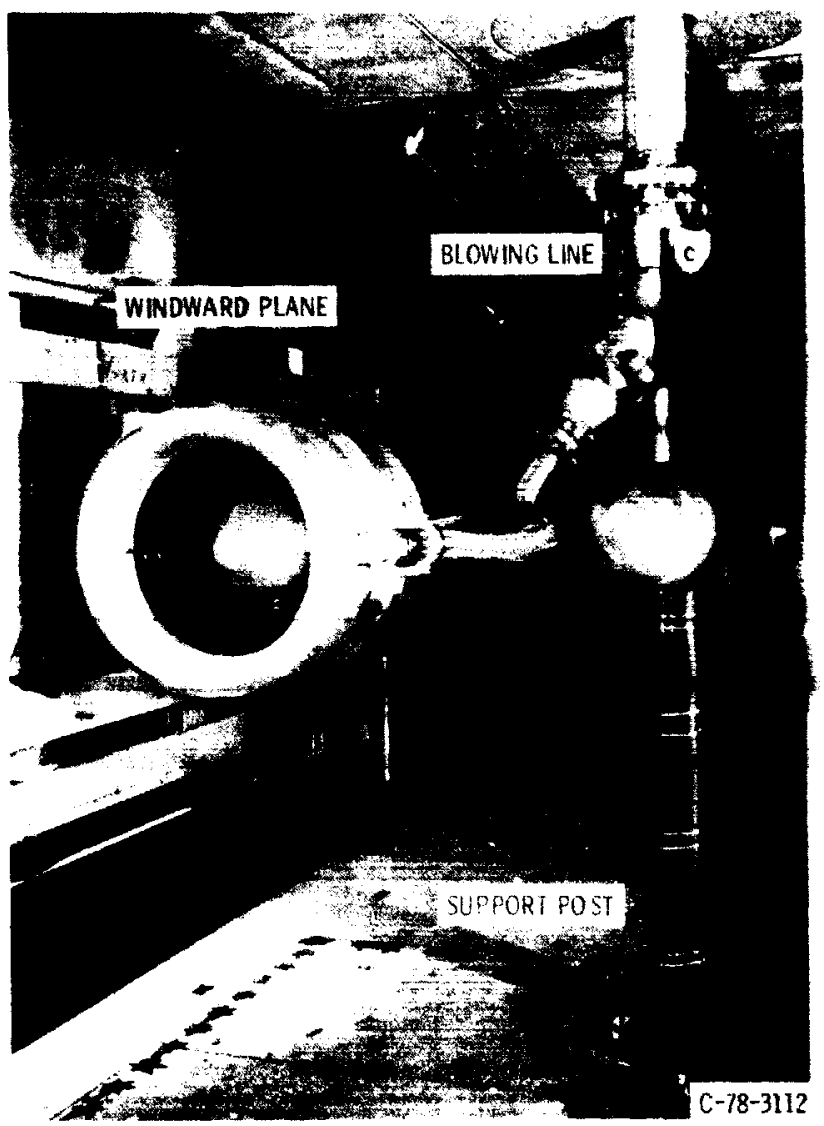

Figure 3. - Model installation in $9 \times 15$ foot wind tunnel.

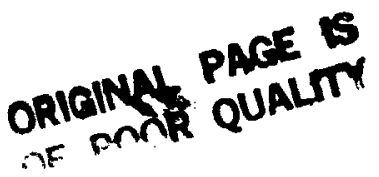



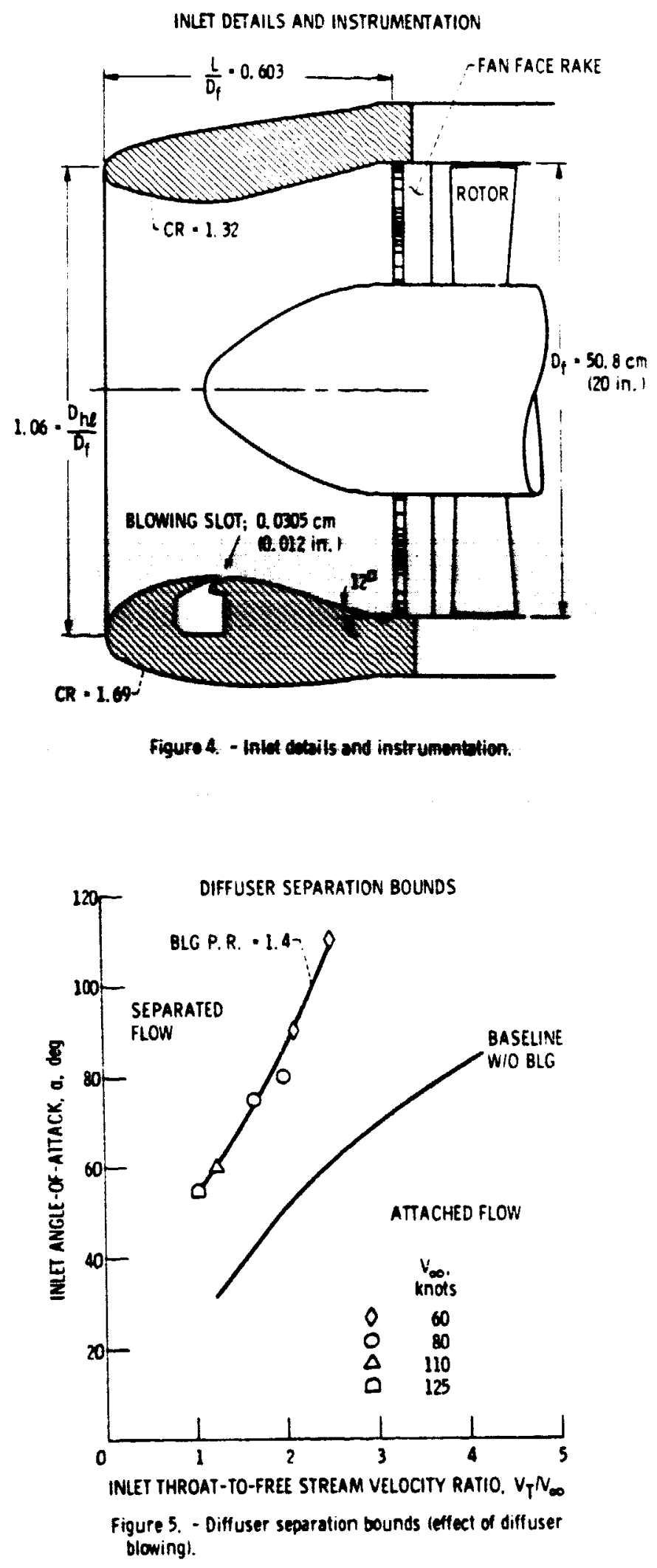

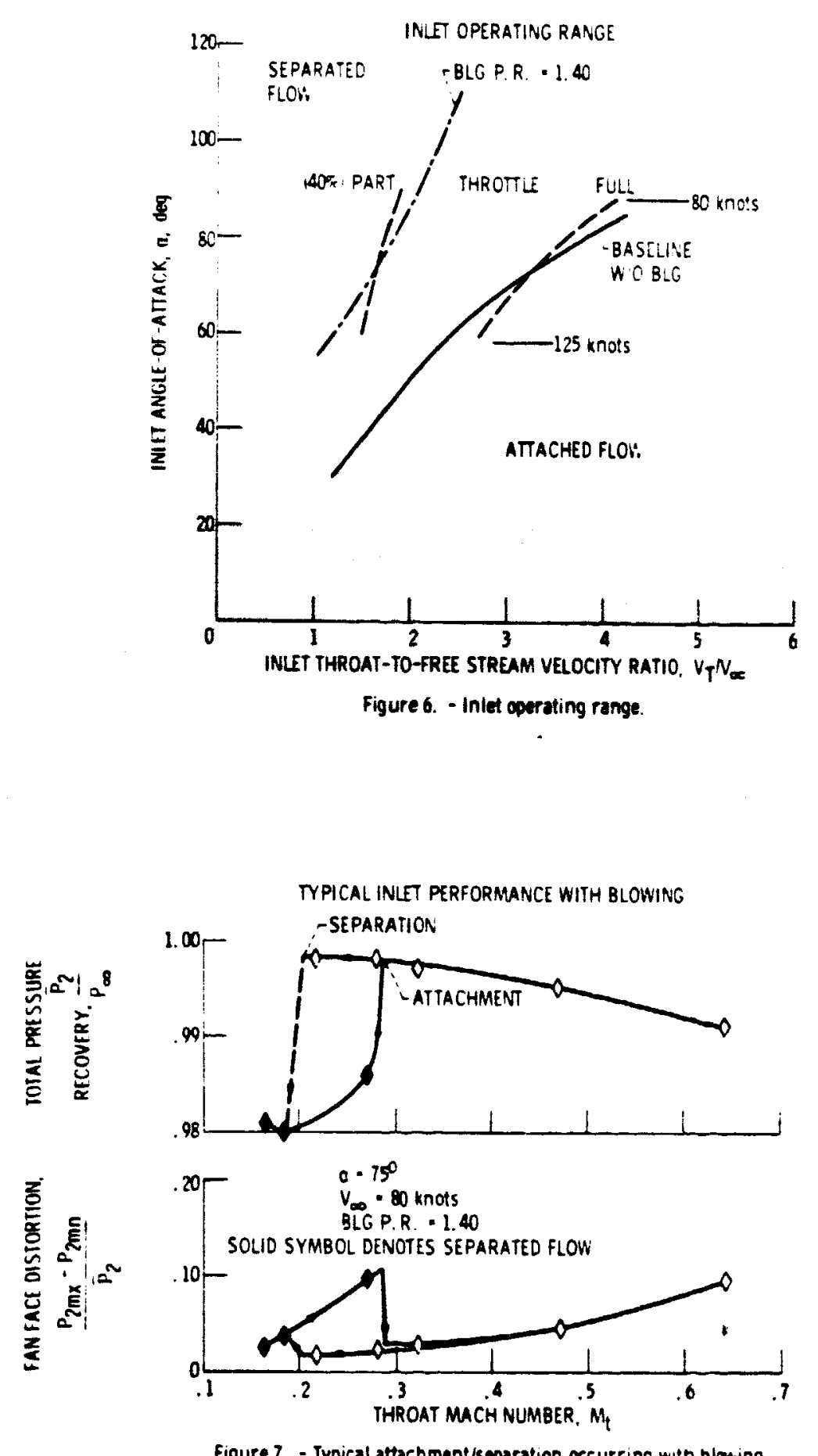

Figure 7. - Typical attachment/separation $\alpha c u r r i n g$ with blowing. 


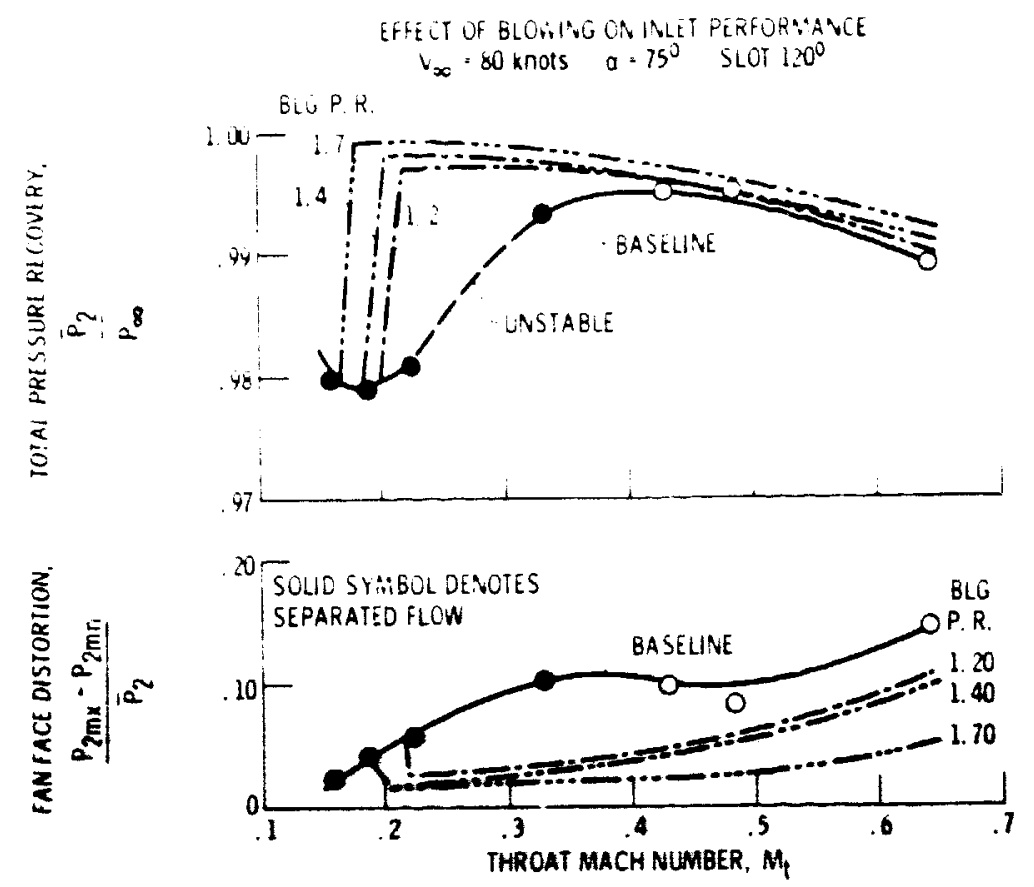

Figure 8. - Effect of diffuser blowing on inlet pertormance.

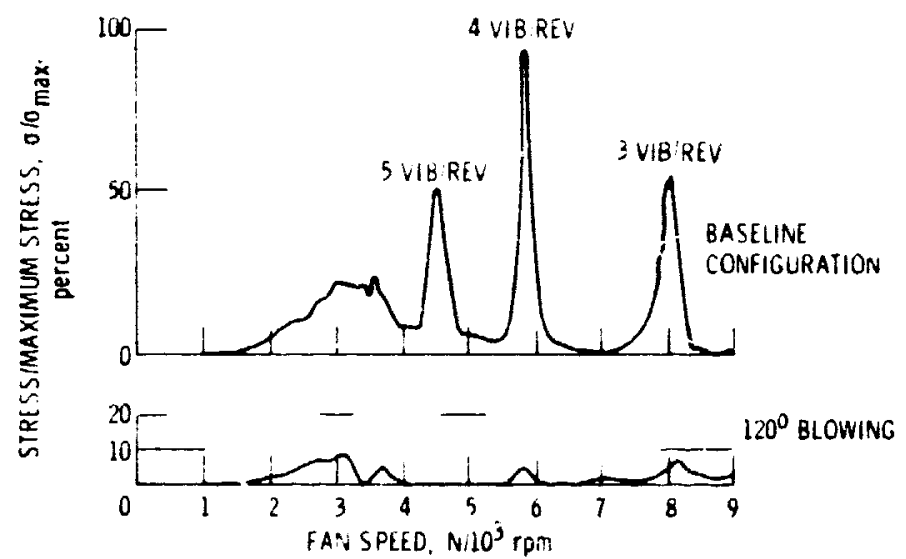

Figure 9. - Effect of blowing on fan blade stress ifirst flatwise bending model, at $v_{0}=04 \mathrm{~m} / \mathrm{sec} 1125 k_{1}$ iotsi and $a=59$, blowing pressure ratio = 1.40 . 


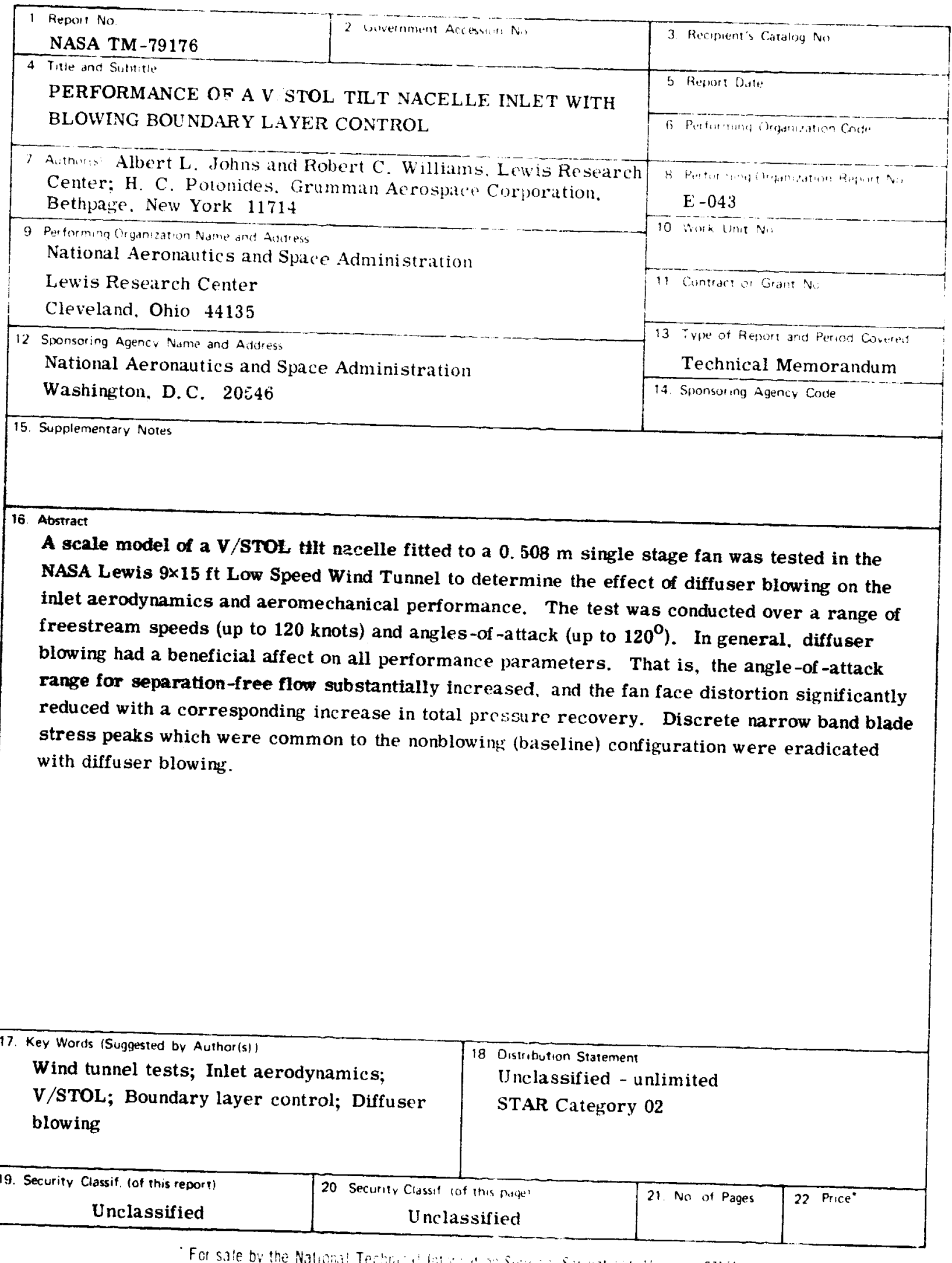

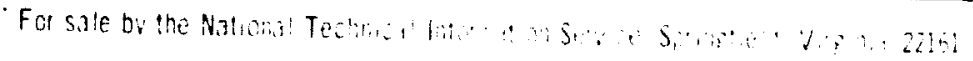



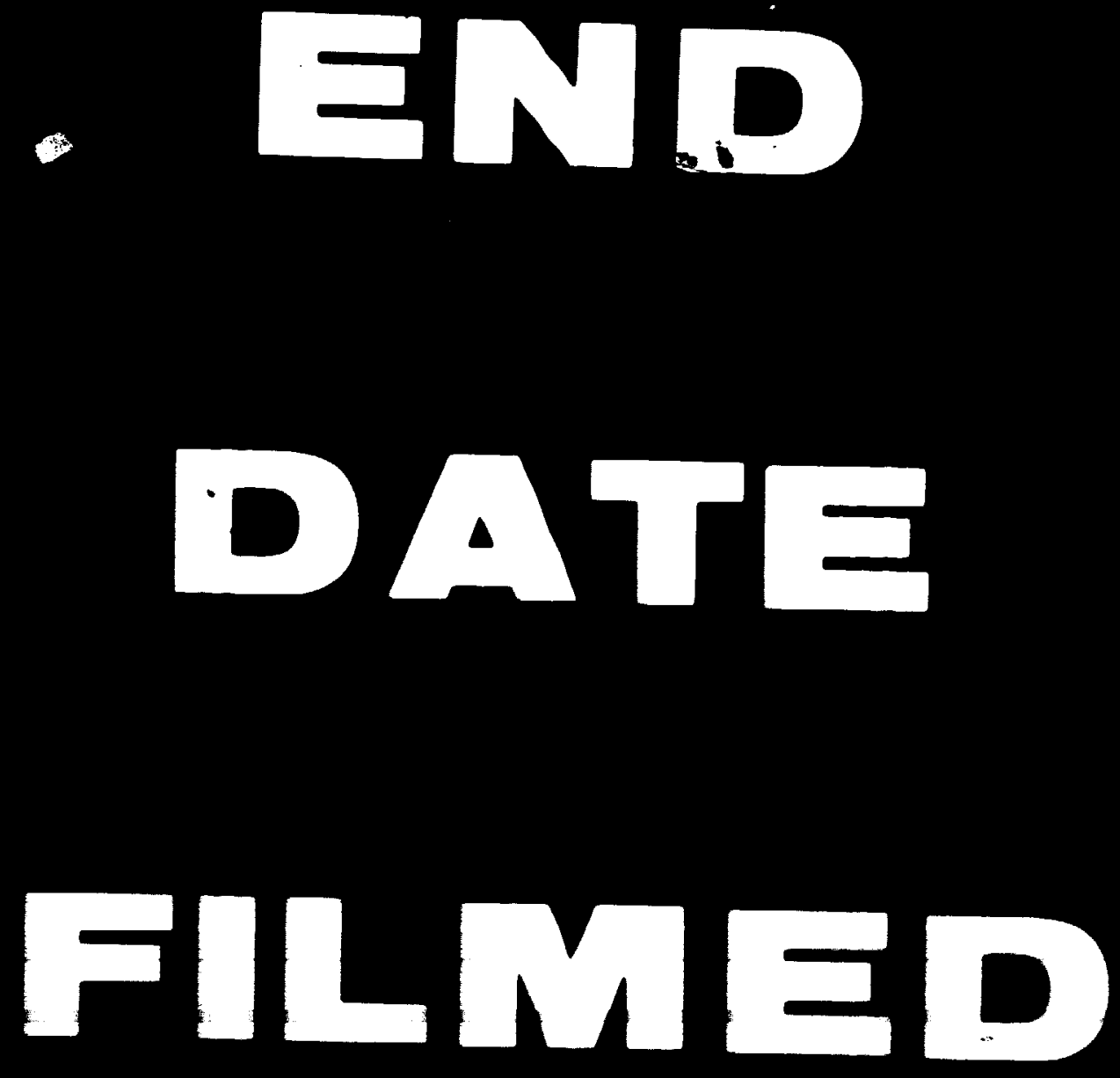

of
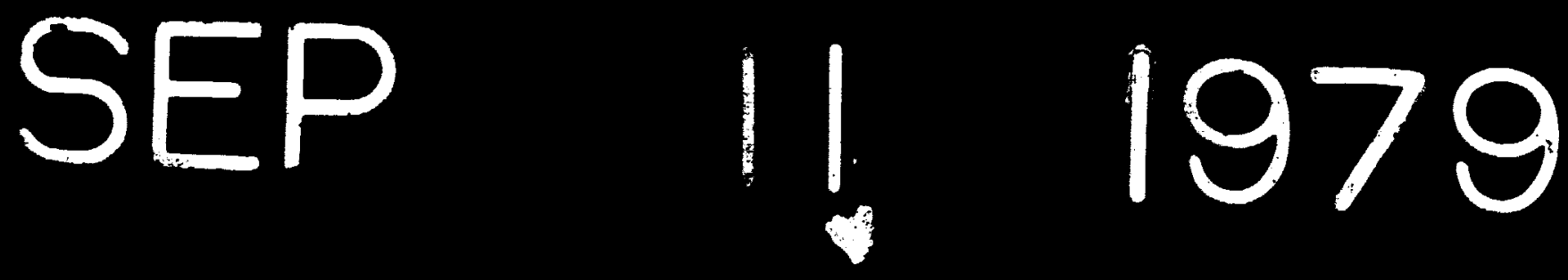